\title{
THE ROLE OF RESILIENCE ON EUdAIMONIC WELL-BEING OF FIRST-YEAR UNDERGRADUATE ENGINEERING STUDENTS
}

\author{
Sahil Saxena, Chirag Variawa \\ University of Toronto \\ sahil.saxena@mail.utoronto.ca
}

\begin{abstract}
First-year undergraduate engineering students are exposed to numerous stressors, including high academic demands and adjusting to new social support networks. Positive adaptations through the use of personal resources e.g. resilience has been associated with improved well-being outcomes in literature. A sample of 8 first-year undergraduate engineering students was examined in terms of $i)$ the prevalence of Eudaimonic WellBeing $(E W B)$ and resilience and ii) the role of resilience on $E W B$. EWB was assessed using the Flourishing Scale and resilience was measured using the Brief Resilience Scale. Findings uncovered low prevalence of EWB and resilience in the study population. The means of both FS and BRS scores were found to be significantly lower in the study population, compared to findings from other empirical studies. No significant relationship was found between resilience and EWB. Areas for future research is discussed.
\end{abstract}

Keywords: transition, engineering, students, mental health, well-being, resilience, personal resources

\section{INTRODUCTION}

The Public Health Agency of Canada (PHAC) defines mental health as "the capacity of each and all of us to feel, think, and act in ways that enhance our ability to enjoy life and deal with the challenges we face. It is a positive sense of emotional and spiritual well-being that respects the importance of culture, equity, social justice, interconnections and personal dignity" [47]. Whereas, the World Health Organization's definition of mental health states, "Mental health is a state of well-being in which an individual realizes his or her own abilities, can cope with the normal stresses of life, can work productively and is able to make a contribution to his or her community." [74]. Both of these definitions point to a central idea that overall mental health is not just the absence of mental illness but also comprises of the state of well-being of the individual. This characterization is aligned with the dual continua model of mental health and illness [34]. A number of studies have provided evidence to the dual continua model, for example in American adults [35], American adolescents (ages 12 to 18) [36], Dutch adults [40], and South-African adults [37]. High levels of mental wellbeing has been associated with preventative effects on the development of mental health problems over time [67]. Thus, in addition to mental illness, mental well-being also serves as an important function in the overall mental health of an individual.

Current research on well-being has been derived from two general perspectives: the hedonic approach and the eudaimonic approach. Hedonic well-being focuses on happiness and defines well-being in terms of pleasure attainment and pain avoidance. Eudaimonic Well-Being (EWB) focuses on the idea of realizing one's unique potential [3], through the means of optimal positive functioning and the act of striving Error! Reference source not found. While both HWB and EWB serve an important role in defining an individual's sense of wellbeing, in the academic context, high levels of EWB in particular has consistently been associated with better academic performance [1][68], and more adaptive coping strategies to manage the student life [21]. These studies motivates a need to study the driving factors that influences EWB in a student.

Individual difference factors such as resilience may serve as an important personal resource or capability that a student can utilize to achieve high levels of EWB. Resilience can be described as the ability of the individual to effectively negotiate, adapt to, or manage significant sources of stress. A number of studies have found resilience to be positively associated with EWB amongst the general population [28][62][66]. This paper aims to explore the relationship between resilience and EWB among first-year undergraduate engineering students.

\section{MOTIVATION AND AIM}

Despite an understanding of the first-year undergraduate engineering environment as being highly pressured and stressful from a student's perspective, there is a lack of research on factors that influences student well- 
being amongst first-year undergraduate engineering students in Canada.

Students transitioning from high school to this environment could potentially face numerous changes. For example, students may have to leave their established routines and social support networks, develop new ones, take on new responsibilities such as independent living, and adapt to new, and often greater, academic challenges. Consequently, this transition marks a time period where there is an increased sensitivity and vulnerability amongst students [20]. Although studies focussed on first-year undergraduate engineering students in Canada are limited, one study of 351 first-year engineering undergraduate students across 7 Canadian universities asked students to self-report how stressed they feel on average on a Likert scale of 1-5 (5 representing the highest stress level). The study found that over $61 \%$ of students responded with a value of 4 or higher [24]. While the demands of university lifestyle are to some extent inherently stressful, negative adaptations to such stressful situations could impact a students' well-being [22][60].

However, positive adaptations to stressors through the optimal use of psychological resources has been associated with promoting well-being. This includes individual level resources such as sense of coherence [58], self-esteem [51], personality hardiness [39], optimism [57], and problemsolving abilities [12][14]. These findings support the notion that students with more positive psychological resources seem to be better equipped to manage student life [46]. Such resources might also represent as ideal points of intervention to ensure students are best equipped to manage such stressors [60].

This study seeks to meet two objectives. The first is to observe the prevalence of EWB and resilience in first-year undergraduate engineering students. The second, is to explore the role of resilience on an individual's EWB within the first-year undergraduate engineering student body from a Canadian university. The hypothesis is that resilience will be positively associated with EWB.

\section{EUDAIMONIC WELL-BEING}

Although various conceptualizations of Eudaimonic Well-Being (EWB) exist in literature, certain parallels can be drawn. In general, high levels of EWB is understood to be achieved through high levels of eudaimonic functioning within the following four facets: (i) personal growth: which refers to realizing one's true potential and is related to variables such as competence and excellence [53], accomplishment and progress [59], constant learning through openness to new experiences, self-esteem and selfefficacy [52] (ii) meaning and purpose: which refers to striving to serve towards a higher purpose and is related to variables such as sense of coherence [4] and self- transcendence [23] (iii) quality relationships: which refers to having a sense of belonging and positive relationships with others and is related to social well-being [34] and (iv) positive attitude: which refers to being able to maintain a positive demeanor in the face of challenges and is related to concepts of hope [65]; and optimism [13]. Hence, the EWB perspective is focused on the blossoming of individual capacities and as a route to achieving full psychological functioning.

In the academic context, EWB is often assessed through a concept known as Psychological Well-Being (PWB) in literature [54][55]. This conceptualization draws from the EWB tenets to present six distinct aspects of human actualization, which are: autonomy, personal growth, selfacceptance, life purpose, mastery, and positive relatedness [52]

PWB is a phenomenon that is important for university students in order to successfully adapt to university life [8]. A study of 1,072 Spanish university students found PWB to be positively associated with adaptive coping strategies (e.g. positive reappraisal, support seeking and planning), while being negatively associated with dysfunctional coping strategies (e.g. ignoring the problem, blaming oneself about the situation or taking refuge in fantasizing thoughts) [21]. Another study surveyed 353 American university students to explore relationships of PWB with optimism, health as a value and engagement to religious and spiritual practices. The results suggested that PWB is positively associated with optimistic attitudes, adopting health promoting behaviours (e.g. performing exercise) and engaging in religious and spiritual practices [11]. Another study surveying 373 Canadian students found respondents who had a higher family income, reported better physical health, expressed a higher degree of satisfaction with their relationships with family, friends, and significant other, indicated a more positive self-image, and experienced less academic stress were found to exhibit a significantly higher level of PWB [15]. These findings reflect that high levels of EWB is important for students making the transition to university [8]. Furthermore, it emphasizes the need to study the factors that influence student EWB.

\section{THEORETICAL FRAMEWORK}

Pathways to EWB can be viewed through the lens of the Conservation of Resources (CoR) theory. The CoR theory [30] proposes that individuals seek to acquire and maintain resources. When these resources are gained, the result is an increase in well-being. According to the CoR theory, there are four kinds of resources that can lead to greater wellbeing, including physical objects (e.g. one's home), personal characteristics (e.g. self-efficacy), conditions (e.g. social support), or energies (e.g. time). 


\section{METHOD}

As per CoR theory, personal characteristics are a type of resource individuals employ to serve as "general resistance" to demands [58] and serve as important determinants of optimal functioning [29][33] Personal resources are those that refer to individuals' sense of their ability to control and impact upon their environment successfully [30] to achieve goals, and stimulate personal growth and development [75]. This paper proposes that resilience serves as a personal characteristic resource resulting in increased EWB when at high levels.

\section{RESILIENCE}

Resilience has been referred to as the personal qualities and skills that allow for an individual's healthy/successful functioning or adaptation within the context of significant adversity or a disruptive life event [16][45][46].

Resilience literature typically falls into two distinct conceptualizations of resilience. One conceptualization positions resilience as a dispositional trait linked to personality (e.g. [6]), while another positions resilience as a learned capability which is dynamic and contextual (e.g. [71][73]) that involves complex interactions between internal characteristics and external conditions [49]. Another, more comprehensive perspective posits that while there are multiple ways of conceptualizing resilience, these divergent views may simply represent different facets of the same construct [45]. So, even if certain underlying innate predispositions for resilience exist, several malleable personal factors and processes for resilience exist as well. For instance, studies looking at the outcomes of resilience interventions show promise for a variety of age groups. One study found that it is possible to promote resilience in children by teaching them better thinking and problem solving skills [43]. Another study demonstrated that teaching resilience strategies (i.e. positive coping strategies) can foster self-efficacy, cognitive control and self-awareness in university students [17]. Similarly, another study demonstrated resilience training in the workplace to benefit employees on a number of positive outcomes such as well-being and performance indicators including lower stress, goal attainment and productivity [2][50]. Such studies provides evidence to support that at least certain facets of resilience could be viewed as a skill that can be developed in individuals [45].

Prior empirical studies demonstrates positive relationship between resilience and the facets of eudaimonic functioning. These include optimism [26] [19] [44][63], self-efficacy [25][42], self-esteem [7][5], meaning and purpose [63][69] and social support [19] [10][27][72]). In this study, we expect resilience to exhibit a positive relationship with EWB.

\subsection{Participants and Procedure}

A sample of 75 students were randomly selected and invited to participate, out of all first-year undergraduate engineering students, who were registered with full course workload during the winter semester at the University of Toronto. Invitations were sent via. an email with a Google Forms link to an online questionnaire. As an incentive to participate in the survey, these students were informed that three winners would be selected based on a draw where each winner would receive a $\$ 20$ gift card to the University of Toronto Bookstore. Out of 75 students who were invited, only 8 students participated and fully completed the online questionnaire. The online questionnaire comprised of the following instruments: The Flourishing Scale (FS) and the Brief Resilience Scale (BRS). Each participant provided informed consent prior to completing the questionnaire. The University of Toronto ethics review board approved all procedures and materials used in this study.

\subsection{Measures}

6.2.1. Flourishing Scale. The Flourishing Scale (FS) [18] is an eight-item self-report instrument. It is a unidimensional construct that combines numerous facets of eudaimonic functioning into a single PWB score. The components that the FS assesses includes: meaning/purpose, positive relationships, engagement, social contribution, competence, self-respect, optimism and social relationships [32]. Each item is phrased in a positive direction using a 7-point Likert scale ranging from 1 (strongly disagree) to 7 (strongly agree). The score is obtained by adding the respondents' scores from each item (ranging from 8 to 56). The FS has been tested on undergraduate students with good psychometric properties, demonstrating its applicability in the university context. The scale has demonstrated good internal reliability (alpha $=0.87$ ) and has been found to correlate well with other measures of PWB including the 54-item scales of Psychological Well-being [53] demonstrating its convergent validity [18].

6.2.2. Brief Resilience Scale. The Brief Resilience Scale (BRS) [63] is a six-item self-report instrument developed to assess the ability to bounce back and recover from stress. Three questions are phrased in the positive direction, while the other three in the negative direction. Participants respond by indicating the extent to which they agree with each of the statements using a five-point Likert scale ranging from 1 (strongly disagree) to 5 (strongly agree). The score is obtained by reverse coding the three negatively phrased questions, and finding the mean of the six items to yield a single score (ranging from 1 to 5 ). The BRS has been tested on undergraduate students with good 
psychometric properties, demonstrating its applicability in the university context. The scale has demonstrated good internal reliability $(\alpha=0.84)$ and has been found to correlate well with other measures of resilience, such as the Connor-Davidson Resilience Scale and the Ego Resiliency Scale [63] demonstrating its convergent validity.

\subsection{Analyses}

To compare any difference in EWB and resilience between our study population and findings from other empirical studies in literature, independent t-tests were conducted to examine the results. Simple linear regression was conducted to examine whether resilience played a role in enhancing EWB. A criterion of $p<0.05$ was adopted to determine statistical significance.

\section{RESULTS}

The number of responses $(\mathrm{N})$, mean, standard deviation (SD) and the $95 \%$ confidence interval for the FS and the BRS can be found in Table 1. To check univariate normality of each measure, one guideline [38] suggested a cut-off of absolute values of 3.0 and 8.0 for skewness and kurtosis, respectively. The skewness and kurtosis for FS was found to be -0.24 and -1.05 respectively. The skewness and kurtosis for BRS was found to be 1.30 and 1.78 respectively. These results indicate that the responses for both measures were relatively normally distributed. All 8 survey respondents provided responses to all questions in each measure. The mean score for the FS was found to be 32.7 (95\% CI: $[25.4,40.0])$ and the mean score for the BRS was found to be 2.6 (95\% CI: [1.98, 3.22]). A relatively high variance in the scores was found for both measures, which is likely due to the low sample size. Both measures were found to be internally reliable, with FS showing excellent internal reliability $(\alpha=0.92)$ and BRS showing good internal reliability $(\alpha=0.87)$.

Although the authors of the FS do not provide a guideline on thresholds for interpreting individual scores, they do present a norm in terms of percentiles to enable relative interpretation of individual scores. The norms are based on a sample of 689 college students comprising of 508 students from 5 American colleges and 181 students from a college in Singapore [18]. The percentile rank of each respondent from our survey, based on their FS score, can be found in Table 2. For the BRS, the authors provide a guideline for interpreting individual scores as follows: 12.99 as "low resilience", 3.00-4.30 as "normal resilience" and 4.31-5.00 as "high resilience" [64]. These are tabulated in Table 2.

The results of the linear regression model to predict EWB (as measured by the FS) based on a student's resilience (as measured by the BRS) can be found in Table 3. The table presents the unstandardized regression coefficient $(\beta)$ with its respective $95 \%$ Confidence Interval $(\mathrm{CI})$, and the standard error $(S E)$. No violation of the assumptions of normality, linearity and homoscedasticity was found. The regression analysis produced a statistically insignificant model $\left(F(1,6)=0.43 ; p=0.54 ; R^{2}=0.07\right)$. The unstandardized regression coefficient of BRS was found to be $\beta=2.943$ (95\% CI: $[-8.05,13.93])$

Table 1: Descriptive Statistics for the scores from the FS and the BRS

\begin{tabular}{|c|c|c|c|c|}
\hline & $N$ & $M$ & SD & $95 \%$ CI \\
\hline FS & 8 & 32.7 & 10.5 & $25.4-40.0$ \\
\hline BRS & 8 & 2.6 & 0.9 & $1.98-3.22$ \\
\hline
\end{tabular}

Table 2: Interpretation of Individual Scores for FS and BRS

\begin{tabular}{|c|c|c|}
\hline Respondent & FS $^{\mathbf{1}}$ & BRS \\
\hline 1 & 1 & Low \\
\hline 2 & 1 & Low \\
\hline 3 & 3 & Low \\
\hline 4 & 5 & Low \\
\hline 5 & 7 & High \\
\hline 6 & 21 & Low \\
\hline 7 & 39 & Normal \\
\hline 8 & 53 & Low \\
\hline
\end{tabular}

- Percentile rank based on norm [18]

Table 3: Linear Regression Results with BRS $(N=8)$

\begin{tabular}{llc}
\hline Term & Coefficient $(\beta)[95 \% \mathrm{CI}]$ & $S E$ \\
\hline Constant & $24.962[-5.202-55.125]$ & 12.327 \\
\hline BRS & $2.943[-8.049-13.934]$ & 4.492 \\
\hline
\end{tabular}

\section{DISCUSSION}

The first aim of the research was to observe the prevalence EWB and resilience in first-year undergraduate engineering students. Student EWB was assessed using the FS, while resilience was assessed using the BRS. Table 3 shows that most of the students in the sample ( 5 out of the 8 students) fall in the bottom $7^{\text {th }}$ or lower percentile relative to the norm, suggesting a relatively very low EWB in these individuals. Moreover, the mean FS score was found to be significantly lower in the study population compared to the norm (i.e. 32.7 vs. $44.97, t(7)=3.30, p<0.01$ ). Relatively low FS scores indicates that the students in this cohort are generally not optimally functioning in one or more facets of eudaimonic functioning including, self-esteem, sense of purpose or meaning, social well-being and maintaining a positive attitude. 
In terms of the prevalence of resilience as measured by the BRS, Table 3 shows that most of the students in the sample (6 out of the 8 students) fall in the "low resilience" category. Moreover, the mean BRS score was found to be significantly lower in the study population, compared to results from other samples of undergraduate students i.e. relative to sample 1 of 128 students ( 2.6 vs. $3.5, t(7)=2.88$, $p<0.05)$ and relative to sample 2 of 64 students (2.6 vs. $3.5, t(7)=2.92, p<0.01)$ [63]. Low BRS scores indicates that the students in this cohort generally see themselves has having a low ability to bounce back from stress. Taking this finding together with the low prevalence of EWB, the results may be indicative of negative adaptations to the numerous changes due to the transition to the first-year undergraduate engineering environment, as maladaptations and poor coping mechanisms has been linked to poor well-being outcomes in literature [21][22][60].

The second aim of the research was to examine the role of resilience on EWB. To examine this, a linear regression model was developed. The results, as summarized in Table 3 , yielded a statistically insignificant model. A high variability in the $95 \%$ confidence intervals of the effect size of BRS on FS was also observed $(\beta=2.943$ (95\% CI: [$8.05,13.93])$ ), which is due to the low sample size of this study. Consequently, the current data was found to be insufficient to allow any direct interpretation of the significance, magnitude and direction of the possible relationship between BRS and FS. It is worthwhile to note, that the $95 \% \mathrm{CI}$ of the BRS coefficient includes effect sizes that are noteworthy and non-trivial in both directions. For example, in the positive direction, a BRS coefficient value of 12 would suggest that just a 1 unit increase in the BRS score, would represent a change in the FS score that corresponds to an increase in the percentile rank from the $7^{\text {th }}$ percentile to the $53^{\text {rd }}$ percentile. A positive relationship between resilience and well-being is generally congruent to empirical studies [56] [61] [70]. On the other hand, an effect in the negative direction is meaningful, as this is contrary to general literature. Future studies engaging larger sample sizes is required to better understand the possible role of resilience on EWB.

\section{LIMITATIONS}

This study has several limitations. One of the major limitations is the low sample size. Future research he unidimensional structure of the FS, we cannot interpret FS scores in relation to the various facets of eudaimonic functioning. Future research may use multi-dimensional instruments such as the Ryff's scales of Psychological Well-Being [53]. Moreover, due to the cross-sectional nature of the study, causality between resilience and EWB cannot be established. The results of this study is subject to response bias because EWB and resilience were measured using self-report instruments [31]. In addition, these results cannot be generalized as it is restricted to a particular cohort of first-year undergraduate engineering students from one Canadian university. More information should be collected in future studies, including the student's demographic data, social environment, learning environment, characteristics of the stressors, and hedonic well-being level.

\section{CONCLUSION AND NEXT STEPS}

Clearly, students vary in their ability to cope with and adjust to new challenges, such as adjusting to the first-year undergraduate engineering environment. EWB is a construct that has been shown to explain this variation in students. Students with high EWB successfully engage in meaningful relationships, positively adapt to challenges and are able to realize their fullest potential [8]. Personal resources may serve as an important determinant to an individual's EWB [29][33]. Consequently, we contend that further studies examining the possible role of personal resources (e.g. resilience) on EWB within first-year undergraduate engineering students in Canada is warranted for two reasons. Firstly, our findings uncovered low prevalence of both EWB and resilience within the cohort, revealing signs of sensitivity and vulnerability amongst these students. Secondly, studies in this area shows promise, as the possible role of personal resources on EWB is theoretically supported (i.e. by CoR theory) and is empirically evidenced in literature, albeit primarily within the general population. Future research directed towards personal resources that are more malleable as opposed to stable intrapersonal constructs is recommended. Such resources may be more amenable to practical implications, such as serving as possible points of intervention [60]

\section{Acknowledgements}

We would like to extend our gratitude to The First Year Office for providing us the resources and opportunity to conduct this study.

\section{References}

[1] A. J. Howell, "Flourishing: Achievement-related correlates of students' well-being," The Journal of Positive Psychology, vol. 4, no. 1, pp. 1-13, 2009.

[2] A. M. Grant, L. Curtayne, and G. Burton, "Executive coaching enhances goal attainment, resilience and workplace well-being: a randomised controlled study," The Journal of Positive Psychology, vol. 4, no. 5, pp. 396-407, 2009.

[3] A. S. Waterman, "Reconsidering happiness: a eudaimonists perspective," The Journal of Positive Psychology, vol. 3, no. 4, pp. 234-252, 2008.

[4] Antonovsky, A. (1993). The structure and properties of the sense of coherence scale. Social Science \& 
Medicine, 36, 725-733. doi:10.1016/02779536(93)90033-Z

[5] Balgiu, Beatrice. (2017). Self-esteem, personality and resilience. Study of a students emerging adults group. Journal of Educational Science and Psychology. VII(LXIX). 93-99.

[6] Bartone, P. T. (2007). Test-retest reliability of the Dispositional Resilience Scale-15, a brief hardiness scale. Psychological Reports, 101(3), 943944. https://doi.org/10.2466/PR0.101.7.943-944

[7] Beutel, Manfred \& Glaesmer, Heide \& Decker, Oliver \& Dr. Fischbeck, Sabine \& Brähler, Elmar. (2009). Life satisfaction, distress, and resiliency across the life span of women. Menopause (New York, N.Y.). 16. 1132-8. 10.1097/gme.0b013e3181a857f8.

[8] Bowman, Nicholas. (2010). The Development of Psychological Well-Being Among First-Year College Students. Journal of College Student Development. 51. 180-200. 10.1353/csd.0.0118.

[9] Bronfenbrenner U. Ecological models of human development. In: Husen T, Postlethwaite $\mathrm{T}$, eds. International Encyclopedia of Education. 2nd ed. Oxford, UK: Pergamon Press; 1994:1643-1647.

[10] Brown, D. L. (2008). African American Resiliency: Examining Racial Socialization and Social Support as Protective Factors. Journal of Black Psychology, 34(1), 32-48. https://doi.org/10.1177/0095798407310538

[11] Burris, Jessica \& Brechting, Emily \& Salsman, John \& Carlson, Charles. (2009). Factors Associated With the Psychological Well-Being and Distress of University Students. Journal of American college health : J of ACH. 57. 536-43. 10.3200/JACH.57.5.536-544.

[12] Carson, David \& Runco, Mark. (1999). Creative Problem Solving and Problem Finding in Young Adults: Interconnections with Stress, Hassles, and Coping Abilities. The Journal of Creative Behavior. 33. 167-188. 10.1002/j.2162-6057.1999.tb01195.x.

[13] Carver, C. S., \& Scheier, M. F. (2002). Optimism. In C. R. Snyder, \& S. J. Lopez (Eds.), Handbook of positive psychology (pp. 231-243). New York, NY: Oxford University Press.

[14] Chinaveh, Mahbobeh. (2013). The Effectiveness of Problem-solving on Coping Skills and Psychological Adjustment. Procedia - Social and Behavioral Sciences. 84. 4-9. 10.1016/j.sbspro.2013.06.499.

[15] Chow, Henry. (2007). Psychological well-being and scholastic achievement among university students in a Canadian Prairie City. Social Psychology of Education. 10. 483-493. 10.1007/s11218-007-9026-y.

[16] Connor, Kathryn \& Davidson, Jonathan. (2003). Development of a new resilience scale: The ConnorDavidson Resilience Scale (CD-RISC). Depression and anxiety. 18. 76-82. 10.1002/da.10113.

[17] Delany, Clare \& Miller, Kimberly \& El-Ansary, Doa \& Remedios, Louisa \& Hosseini, Ash \& McLeod, S.
(2015). Replacing stressful challenges with positive coping strategies: a resilience program for clinical placement learning. Advances in health sciences education : theory and practice. 20. 10.1007/s10459. 015-9603-3.

[18] Diener, E., Wirtz, D., Tov, W., Kim-Prieto, C., Choi, D., Oishi, S., \& Biswas-Diener, R. (2009). New measures of well-being: Flourishing and positive and negative feelings. Social Indicators Research, 39, 247 266.

[19] F. Sabouripour and S. B. Roslan, "Resilience, Optimism and Social Support among International Students," Asian Social Science, vol. 11, no. 15, 2015.

[20] Fisher, S. (1994). Stress in academic life: The mental assembly line. Society for Research into Higher Education; Open University Press.

[21] Freire, C., Del Mar Ferradás, M., Valle, A., Núñez, J. C., \& Vallejo, G. (2016). Profiles of psychological well-being and coping strategies among university students. Frontiers in Psychology, 7, Article 1554.

[22] Friedlander, Laura \& Reid, Graham \& Shupak, Naomi \& Cribbie, Robert. (2007). Social Support, SelfEsteem, and Stress as Predictors of Adjustment to University Among First-Year Undergraduates. Journal of College Student Development. 48. 259-274. 10.1353/csd.2007.0024.

[23] Garcia-Romeu, A. (2010). Self-transcendence as a measurable transpersonal construct. The Journal of Transpersonal Psychology, 42, 26-47.

[24] Gerrard, D., \& Variawa, C. (2018, June), Bridges and Barriers: A Multi-year Study of Workload-related Learning Experiences from Diverse Student and Instructor Perspectives in First-year Engineering Education Paper presented at 2018 ASEE Annual Conference \& Exposition , Salt Lake City, Utah. https://peer.asee.org/30156

[25] Gillespie, Brigid \& Chaboyer, Wendy \& Wallis, Marianne \& Grimbeek, Peter. (2007). Resilience in the operating room: Developing and testing of a resilience model. Journal of advanced nursing. 59. 427-38. 10.1111/j.1365-2648.2007.04340.x.

[26] H. Souri and T. Hasanirad, "Relationship between Resilience, Optimism and Psychological Well-Being in Students of Medicine," Procedia - Social and Behavioral Sciences, vol. 30, pp. 1541-1544, 2011

[27] Hamdan- Mansour, Ayman \& Azzeghaiby, Saleh \& Alzoghaibi, Ibrahim \& Badawi, Talal \& Nassar, Omayyah \& Shaheen, Abeer. (2014). Correlates of resilience among university students. wulfenia. 21 . 342-351.

[28] He F., Cao R., Feng Z., Guan H., Peng J. (2013). The impacts of dispositional optimism and psychological resilience on the subjective well-being of burn patients: a structural equation modelling analysis. PLoS ONE 8:e82939 10.1371/journal.pone.0082939 
[29] Hobfoll, S. E. (1989). Conservation of resources: A new attempt at conceptualizing stress. American Psychologist, 44(3), 513524. https://doi.org/10.1037/0003-066X.44.3.513

[30] Hobfoll, S. E., Johnson, R. J., Ennis, N., \& Jackson, A. P. (2003). Resource loss, resource gain, and emotional outcomes among inner city women. Journal of Personality and Social Psychology, 84(3), 632643. https://doi.org/10.1037/0022-3514.84.3.632

[31] Holtgraves T. Social desirability and self-reports: testing models of socially desirable responding. Personal Soc Psychol Bull. 2004;30:161-72.

[32] Hone, L.C., Jarden, A., Schofield, G.M., \& Duncan, S. (2014). Measuring flourishing: The impact of operational definitions on the prevalence of high levels of wellbeing. International Journal of Wellbeing, 4(1), 62-90. doi:10.5502/ijw.v4i1.4

[33] Judge, T. A., \& Bono, J. E. (2001). Relationship of core self-evaluations traits-self-esteem, generalized selfefficacy, locus of control, and emotional stabilitywith job satisfaction and job performance: A metaanalysis. Journal of Applied Psychology, 86(1), 8092. https://doi.org/10.1037/0021-9010.86.1.80

[34] Keyes, C. L. M. (2002). The mental health continuum: From languishing to flourishing in life. Journal of Health and Social Behavior, 43, 207-222.

[35] Keyes, C. L. M. (2005). Mental illness and/or mental health? Investigating axioms of the complete state model of health. Journal of Consulting and Clinical Psychology, 73, 539-548.

[36] Keyes, C. L. M. (2006). Mental health in adolescence: Is America's youth flourishing? American Journal of Orthopsychiatry, 76, 395-402.

[37] Keyes, C. L. M., Wissing, M., Potgieter, J., Temane, M., Kruger, A., \& van Rooy, S. (2008). Evaluation of the Mental Health Continuum-Short Form (MHC-SF) in Swetsanaspeaking South Africans. Clinical Psychology and Psychotherapy, 15, 181-192.

[38] Kline, T. J. (2005). Psychological testing: A practical approach to design and evaluation. Thousand Oaks, CA: SAGE Publications, Inc. doi: $10.4135 / 9781483385693$

[39] Kobasa, S. C. (1979). Stressful life events, personality, and health: An inquiry into hardiness. Journal of Personality and Social Psychology, 37(1), 111. https://doi.org/10.1037/0022-3514.37.1.1

[40] Lamers, S. M. A., Westerhof, G. J., Bohlmeijer, E. T., Ten Klooster, P. M., \& Keyes, C. L. M. (2011). Evaluating the psychometric properties of the Mental Health Continuum-Short Form (MHC-SF) in the Dutch population. Journal of Clinical Psychology, 67, 99110.

[41] Li, M.-h., \& Yang, Y. (2009). Determinants of problem solving, social support seeking, and avoidance: A path analytic model. International Journal of Stress
Management, 16(3),
https://doi.org/10.1037/a0016844

[42] Li, Ming-hui. (2008). Relationships among stress coping, secure attachment, and the trait of resilience among Taiwanese college students. 42. 312-325.

[43] Lisa H. Jaycox, Karen J. Reivich, Jane Gillham, Martin E.P. Seligman, Prevention of depressive symptoms in school children, Behaviour Research and Therapy, Volume 32, Issue 8, 1994, Pages 801-816, ISSN 00057967, https://doi.org/10.1016/0005-7967(94)90160-0.

[44] Luthans, F., Avolio, B. J., Avey, J. B., \& Norman, S. M. (2007). Positive psychological capital: Measurement and relationship with performance and satisfaction. Personnel Psychology, 60(3), 541-572. https://doi.org/10.1111/j.1744-6570.2007.00083.x

[45] Luthar, S. S., Cicchetti, D., \& Becker, B. (2000). The construct of resilience: a critical evaluation and guidelines for future work. Child development, 71(3), 543-562. https://doi.org/10.1111/1467-8624.00164

[46] Masten AS, Obradovic J. Competence and resilience in development. Ann N Y Acad Sci 2006;1094:13-27.

[47] Measuring positive mental health in Canada: construct validation of the Mental Health Continuum," Health Promotion and Chronic Disease Prevention in Canada, vol. 37, no. 4, pp. 311-311, Apr. 2017.

[48] P. S. Schmutte and C. D. Ryff, "Personality and wellbeing: Reexamining methods and meanings," Journal of Personality and Social Psychology, vol. 73, no. 3, pp. 549-559, 1997.

[49] Pangallo, A., Zibarras, L., Lewis, R., \& Flaxman, P. (2015). Resilience through the lens of interactionism: A systematic review. Psychological Assessment, 27(1), 1-20. https://doi.org/10.1037/pas0000024

[50] Pipe, Teresa Britt, Vicki L Buchda, Susan Launder, Barb Hudak, Lynne E. Hulvey, Katherine E Karns and Debra K Pendergast. "Building personal and professional resources of resilience and agility in the healthcare workplace." Stress and health : journal of the International Society for the Investigation of Stress 28 1 (2012): 11-22 .

[51] Rosenberg, M. (1985). "Self-concept and psychological well-being in adolescence" in The development of the self. ed. R. L. Leary (New York: Academic Press), 205-246.

[52] Ryan, R. M., \& Deci, E. L. (2001). On happiness and human potentials: A review of research on hedonic and eudaimonic well-being. Annual Review of Psychology, 52(1), 141-166. doi:10.1146/annurev.psych.52.1.141

[53] Ryff, C. D. (1989). Happiness is everything, or is it? Explorations on the meaning of psychological wellbeing. Journal of Personality and Social Psychology, 57(6), 1069-1081. 
[54] Ryff, Carol \& Singer, Burton. (1998). The Contours of Positive Human Health. Psychological Inquiry. 9. 10.1207/s15327965pli0901_1.

[55] Ryff, Carol \& Singer, Burton. (2000). Interpersonal Flourishing: A Positive Health Agenda for the New Millennium. Personality and Social Psychology Review - PERS SOC PSYCHOL REV. 4. 30-44. 10.1207/S15327957PSPR0401_4.

[56] Sagone, Elisabetta and Maria Elvira De Caroli. "Relationships between Psychological Well-being and Resilience in Middle and Late Adolescents." (2014).

[57] Scheier, M. F., \& Carver, C. S. (1992). Effects of optimism on psychological and physical well-being: Theoretical overview and empirical update. Cognitive Therapy and Research, 16(2), 201228. https://doi.org/10.1007/BF01173489

[58] Schnyder, U., Büchi, S., Sensky, T., \& Klaghofer, R. (2000). Antonovsky's Sense of Coherence: Trait or state? Psychotherapy and Psychosomatics, 69(6), 296302. https://doi.org/10.1159/000012411

[59] Seligman, M. E. P. (2011). Flourish. A new understanding of happiness and well-being - and how to achieve them. London: Nicholas Brealey.

[60] Sharp, J., Theiler, S. A Review of Psychological Distress Among University Students: Pervasiveness, Implications and Potential Points of Intervention. Int $\mathbf{J}$ Adv Counselling 40, 193-212 (2018). https://doi.org/10.1007/s10447-018-9321-7

[61] Souri, Hosein \& Hasanirad, Turaj. (2011). Relationship between Resilience, Optimism and Psychological Well-Being in Students of Medicine. Procedia - Social and Behavioral Sciences. 30. 1541-1544. 10.1016/j.sbspro.2011.10.299.

[62] Smith J. L., Hollinger-Smith L. (2015). Savoring, resilience, and psychological well-being in older adults. Aging Ment. Health 19 192-200. $10.1080 / 13607863.2014 .986647$

[63] Smith, B.W., Dalen, J., Wiggins, K. et al. The brief resilience scale: Assessing the ability to bounce back. Int. J. Behav. Med. 15, 194-200 (2008). https://doi.org/10.1080/10705500802222972

[64] Smith, B.W., Epstein, E.E., Oritz, J.A., Christopher, P.K., \& Tooley, E.M. (2013). The Foundations of Resilience: What are the critical resources for bouncing back from stress? In Prince-Embury, S. \& Saklofske, D.H. (Eds.), Resilience in children, adolescents, and adults: Translating research into practice, The Springer series on human exceptionality (pp. 167-187). New York, NY: Springer.

[65] Snyder, C. R. (1995). Conceptualizing, measuring and nurturing hope. Journal of Counselling and Development, 73, 355-360. doi:10.1002/j.15566676.1995.tb01764.X

[66] Souri, Hosein \& Hasanirad, Turaj. (2011). Relationship between Resilience, Optimism and Psychological
Well-Being in Students of Medicine. Procedia - Social and Behavioral Sciences. 30. 1541-1544. 10.1016/j.sbspro.2011.10.299.

[67] Suldo, S. M., \& Shaffer, E. J. (2008). Looking beyond psychopathology: The dual-factor model of mental health in youth. School Psychology Review, 37, 52-68.

[68] Suldo, S., Thalji, A., \& Ferron, J. (2011). Longitudinal academic outcomes predicted by early adolescents' subjective well-being, psychopathology, and mental health status yielded from a dual factor model. The Journal of Positive Psychology, 6(1), 17-30. doi: 10.1080/17439760.2010.536774

[69] Tugade, M. M., \& Fredrickson, B. L. (2004). Resilient Individuals Use Positive Emotions to Bounce Back From Negative Emotional Experiences. Journal of Personality and Social Psychology, 86(2), 320-333. https://doi.org/10.1037/0022-3514.86.2.320

[70] Vinayak, S., \& Judge, J. (2018). Resilience and Empathy as Predictors of Psychological Wellbeing among Adolescents.

[71] Wagnild, GM \& Young, HM 1993, 'Development and psychometric evaluation of the Resilience Scale.', Journal of Nursing Measurement, vol. 1, no. 2, pp. 165-178.

[72] Wilks, Scott \& Spivey, Christina. (2010). Resilience in Undergraduate Social Work Students: Social Support and Adjustment to Academic Stress1. Social Work Education. 29. 276-288. 10.1080/02615470902912243.

[73] Winwood, P.C., Colon, R., and McEwen, K., 2013. A practical measure of workplace resilience: developing the resilience at work scale. Journal of occupational and environmental medicine, 55 (10), 1205-1212.

[74] World Health Organization. (2005). Promoting mental health: Concepts, emerging evidence, practice. Geneva: WHO.

[75] Xanthopoulou, D., Bakker, A. B., Demerouti, E., \& Schaufeli, W. B. (2009). Work engagement and financial returns: A diary study on the role of job and personal resources. Journal of Occupational and Organizational Psychology, 82(1), 183200. https://doi.org/10.1348/096317908X285633 